\title{
Hybrid alternate approach for complex radiation-induced valvular disease
}

\author{
Pierre Olivier Dionne, MD, MSc, ${ }^{\mathrm{a}}$ Mackram F. Eleid, MD, ${ }^{\mathrm{b}}$ Hartzell V. Schaff, MD, ${ }^{\mathrm{a}}$ and \\ Simon Maltais, MD, PhD, ${ }^{a}$ Rochester, Minn
}

\author{
From the ${ }^{\mathrm{a}}$ Division of Cardiovascular Surgery, and ${ }^{\mathrm{b}}$ Department of Cardiovascular Medicine, Mayo Clinic, Ro- \\ chester, Minn. \\ Disclosures: Authors have nothing to disclose with regard to commercial support. \\ Received for publication Jan 24, 2018; revisions received March 27, 2018; accepted for publication March 29 \\ 2018; available ahead of print May 9, 2018. \\ Address for reprints: Simon Maltais, MD, PhD, Mayo Clinic, 1216 2nd St SW, Rochester, MN 55902 (E-mail: \\ maltais.simon@mayo.edu). \\ J Thorac Cardiovasc Surg 2018;156:e147-9 \\ $0022-5223 / \$ 36.00$ \\ Copyright (c) 2018 by The American Association for Thoracic Surgery \\ https://doi.org/10.1016/j.jtcvs.2018.03.127
}

Radiation-induced heart disease is a challenging condition, and patients often present with a number of difficult cardiac conditions, such as ascending aorta calcification, mitral valve (MV) disease with variable degree of mitral annular calcification (MAC), coronary artery disease, aortic valve pathology, severe diastolic dysfunction, and multiple previous cardiac interventions, which complicates the treatment strategy. Several techniques have been described to treat the heavily calcified MV annulus during MV replacement. ${ }^{1}$ Most of these techniques require some degree of annular calcium débridement, which may increase the risk of atrioventricular groove disruption. For patients with isolated MV stenosis and severe MAC, we have already described an alternate sternotomy approach that uses a conduit from the aortic stenosis atrium (LA) to the left ventricle (LV). ${ }^{2}$

We describe the complex situation of a morbidly obese patient with radiation-induced heart disease and a history of 2 previous bypass interventions who presented with severe symptomatic aortic stenosis, severe mitral stenosis with severe MAC, and associated porcelain ascending aorta. We present the case of this patient, who underwent a hybrid approach consisting of LA-LV conduit placement through a left thoracotomy for severe mitral stenosis and a transcatheter aortic valve replacement (TAVR) for severe aortic stenosis.

\section{CASE REPORT}

A 48-year-old woman with severe radiation-induced valve disease, porcelain aorta, severe MV stenosis with severe MAC, severe aortic stenosis, and a history of 2 previous coronary artery bypass grafting procedures was referred to our institution because of advanced heart failure and home oxygen therapy. Other significant medical history included severe obesity (body mass index of $51 \mathrm{~kg} / \mathrm{m}^{2}$ ), pulmonary hypertension (right ventricular systolic pressure of

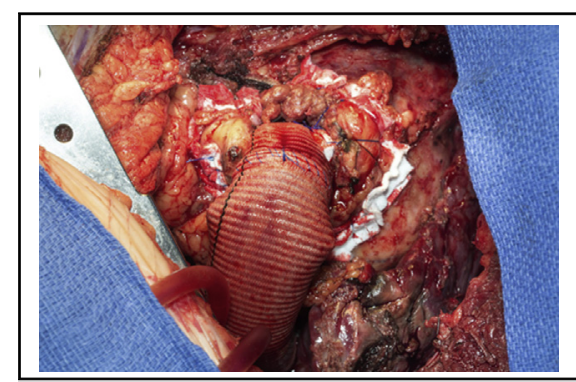

Completion of the left atrial to left ventricular apex anastomosis with a valved conduit.

\section{Central Message}

We present a hybrid approach consisting of LALV conduit placement through a thoracotomy for severe mitral stenosis and transcatheter aortic valve replacement for severe aortic stenosis.

See Editorial Commentary page e151.

$79 \mathrm{~mm} \mathrm{Hg}$ ), and diabetes mellitus. The patient had undergone chest radiotherapy for Hodgkin lymphoma.

The preoperative transthoracic echocardiogram showed normal LV ejection fraction, severe MV and aortic valve stenosis (MV mean gradient of $18 \mathrm{~mm} \mathrm{Hg}$ and aortic valve mean gradient of $40 \mathrm{~mm} \mathrm{Hg}$ ), a severely calcified $\mathrm{MV}$ annulus, and mild mitral regurgitation (Figure 1). Chest computed tomography showed a porcelain aorta. The patient was offered LA-LV conduit placement through a left thoracotomy, combined with staged TAVR.

The patient was positioned in a right lateral decubitus position (Figure 2, A). We achieved peripheral arterial and venous cannulation through the left common femoral artery and vein. Right lung ventilation was achieved with doublelumen endotracheal intubation. A left thoracotomy was carried over the fifth rib. Dissection was carried down to the apex of the heart and the confluence between the left lower pulmonary vein and LA. After heparin administration, cardiopulmonary bypass was initiated. We tangentially clamped this confluence and performed an end-to-side anastomosis of the 26-mm conduit with continuous 4-0 Prolene suture (Ethicon, Inc, Somerville, NJ). We then sutured a reversed 23-mm bileaflet mechanical valve (Abbott Laboratories, Abbott Park, Ill) from outside the graft (Figure 2, B). An apical left ventriculotomy was performed (Figure 2, $C$ ), 


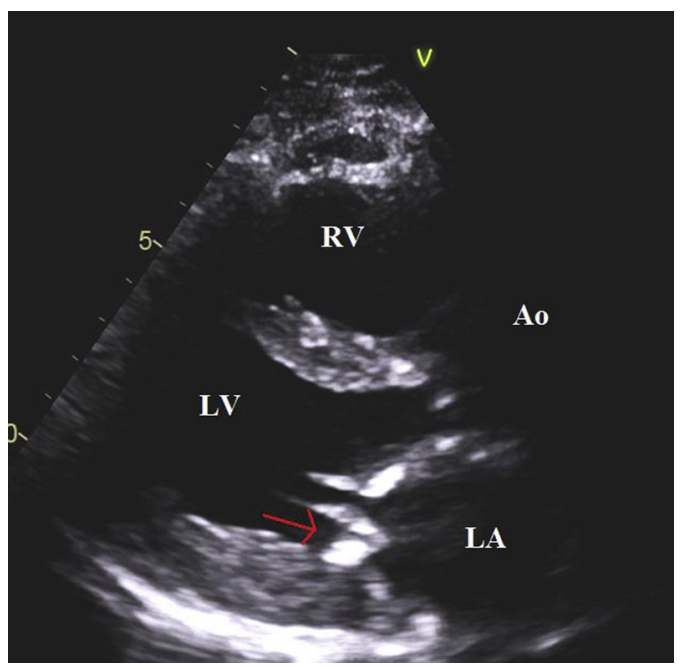

FIGURE 1. Preoperative transthoracic echocardiographic parasternal long-axis view shows extensive mitral annular calcification (red arrow) and a small aortic annulus. $R V$, Right ventricle; $A o$, aortic root; $L V$, left ventricle; $L A$, left atrium.

and the anastomosis of the conduit to the apex was performed during ventricular fibrillatory arrest with 12 interrupted 2-0 Ethibond (Ethicon) sutures with polytetrafluoroethylene felts reinforced with a running 20 Prolene suture (Figure 2,D). Deairing was performed with an 18-gauge needle at the LV apex before attempting to wean the patient from cardiopulmonary bypass. Intraoperative transesophageal echocardiography showed an improved native $\mathrm{MV}$ mean gradient of $8 \mathrm{~mm} \mathrm{Hg}$, in contrast with the 18- $\mathrm{mm} \mathrm{Hg}$ preoperative gradient, and appropriate flow through the designed conduit. A few days later, we subsequently performed a transfemoral TAVR procedure in the hybrid suite. Unfortunately, the patient died approximately 4 months after surgery at the hospital as a result of deconditioning.

\section{DISCUSSION}

Radiation heart valve disease, especially in the context of multiple previous cardiac interventions, represents a complex entity. For these cases, a hybrid innovative approach can be performed to alleviate complications related to porcelain aorta, multiple reentry, or MAC. Our technique differs slightly from the description by Wright and colleagues, ${ }^{3}$ in which proximal anastomosis to the LA is performed at the interatrial groove, as well as the description by Said and Schaff, ${ }^{2}$ in which proximal anastomosis to the LA is
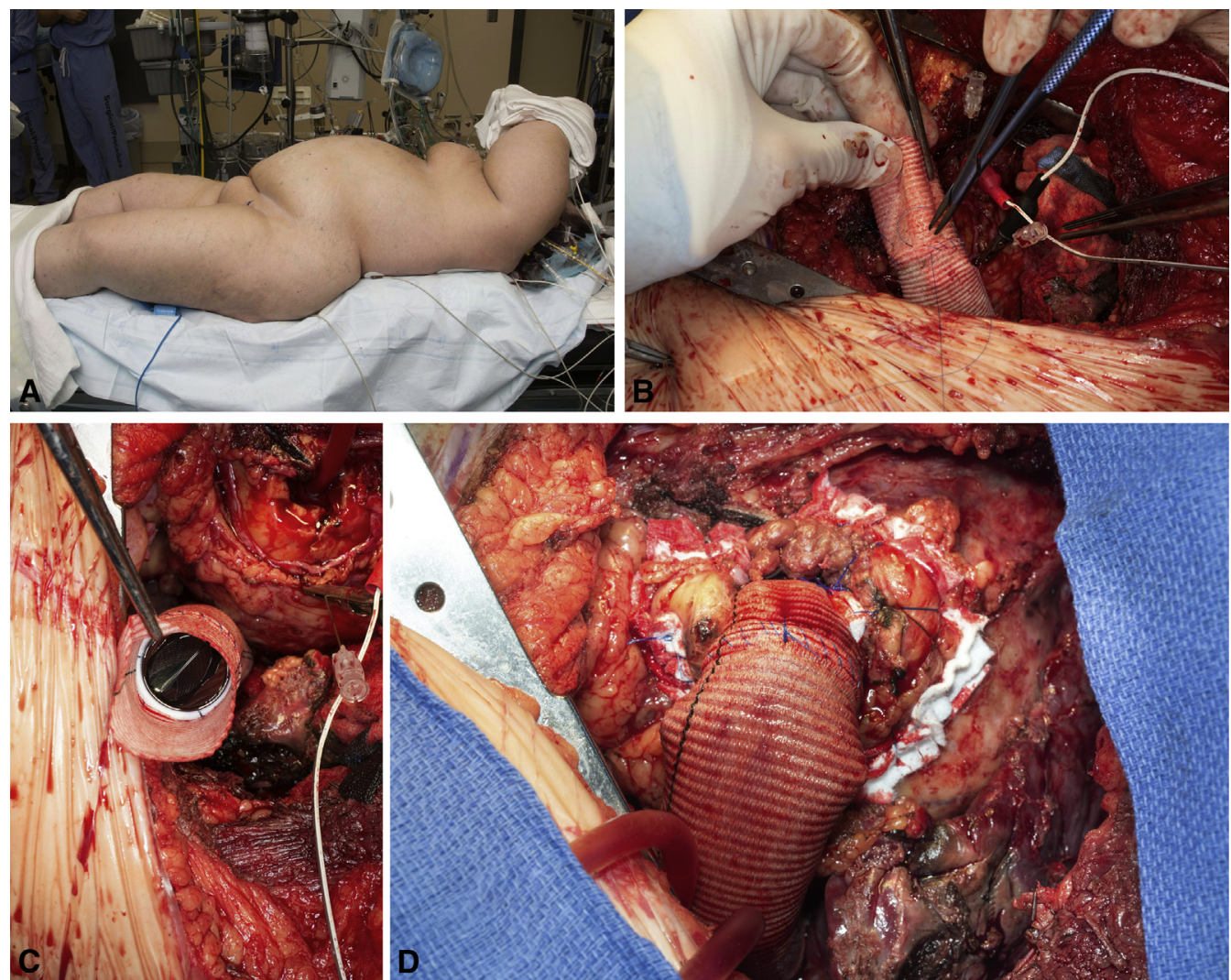

FIGURE 2. Completion of the left atrium-left ventricle apex anastomosis with a valved conduit. A, Positioning. B, External suturing of the mechanical valve to the conduit. C, En face view of the mechanical valve (bottom left) and the left ventricle apex (top right). D, Completed distal anastomosis of the conduit to the left ventricular apex. 
performed at the appendage. These techniques, although similar to the one we describe here, require sternotomy or access to the LA appendage, which are avoided with our left thoracotomy strategy. The confluence between the LA and the lower left pulmonary vein is readily accessible through a left thoracotomy, even in patients with multiple patent bypass grafts. Although we elected to treat the aortic valve with a TAVR procedure, one might even eventually consider performing LA-LV conduit placement and sequential placement of a valved conduit between the LV and the descending aorta through this left thoracotomy approach.

\section{References}

1. Smedira NG. Mitral valve replacement with a calcified annulus. Oper Tech Thorac Cardiovasc Surg. 2003;8:2-13.

2. Said SM, Schaff HV. An alternate approach to valve replacement in patients with mitral stenosis and severely calcified annulus. J Thorac Cardiovasc Surg. 2014; 147:e76-8.

3. Wright JS, Thomson DS, Warner G. Mitral valve bypass by valved conduit. Ann Thorac Surg. 1981;32:294-6. 